\title{
sciendo
}

Transport and Telecommunication, 2021, volume 22, no. 3, 332-342

Transport and Telecommunication Institute, Lomonosova 1, Riga, LV-1019, Latvia

DOI $10.2478 /$ ttj-2021-0026

\section{A DIGITAL OR SUSTAINABLE SMALL AND MEDIUM-SIZED PORT? SUSTAINABLE PORT BLUEPRINT IN THE BALTIC SEA REGION BASED ON PORT BENCHMARKING}

\author{
Christopher Meyer $^{1,2}$, Laima Gerlitz $^{2}$, Robert Philipp $^{2}$, Vytautas Paulauskas $^{3}$ \\ ${ }^{1}$ Tallinn University of Technology, Ehitajate tee 5, 19086 Tallinn, Estonia \\ ${ }^{2}$ Hochschule Wismar, University of Applied Sciences: Technology, Business and Design, Philipp-Müller- \\ Str. 14, 23966 Wismar, Germany \\ ${ }^{3}$ Klaipeda University, H. Manto g. 84, 92294 Klaipeda, Lithuania \\ christopher.meyer@hs-wismar.de \\ laima.gerlitz@hs-wismar.de \\ robert.philipp@hs-wismar.de \\ vytautaskltc@gmail.com
}

\begin{abstract}
Small and medium-sized ports (SMSPs) in the Baltic Sea Region (BSR) are caught in a dilemma of less financial support by the European funding programmes due to their peripheral position in the TEN-T Core Network. Most of the BSR ports belong to the TEN-T Comprehensive Network, which is rationally less important in the topical financial, infrastructural and policy discourses. Despite this, BSR ports are of a colossal importance for the regional economic development serving as gateways for the individual regions and drivers of socio-economic and environmental transition. In addition, ports are essential in pursuing new innovation avenues. The environmental targets published by the European Commission for maritime sector in 2030 and 2050 are applicable for SMSPs as well, creating further obstacles and future challenges on the one hand, but opening new horizons to grow and innovate on the other one. A successful environmental and digital transformation going hand in hand in SMSPs enable sustainable boost of sustainable development. Thus, as a first step, the assessment of sustainable readiness in SMSPs is incumbent in order to implement tailor-made solutions on individual basis, by ensuring efficient usage of available resources and capabilities. In line with the Connect2SmallPorts project, part-financed by the INTERREG South Baltic Programme, 38 SMSPs in the BSR were approached to mapping their digital readiness according to the methodology of the Digital Readiness Index for Ports (DRIP), published within the project in 2020. Building upon this, this paper introduces the idea of digital and environmental twinning to conclude on sustainable development potentials in SMSPs with an adaptation of the DRIP score. Hence, the research contributes to the sustainable port concept and illustrates the positioning of SMSPs in the progress of sustainable development
\end{abstract}

Keywords: Small and medium-sized ports, Baltic Sea Region, sustainable port, Digital benchmarking, sustainable development

\section{Introduction}

European seaports are in process of digital transformation identifying high potentials for performance improvements. As logistical and trans-national nodes in global supply chains, ports are crucial for economic development on regional, national and European level. Hence, they are facing increasing pressure on optimising their activities with respect to not only economic but also energy and environmental obstacles.

In this vein, recent discourse on port development is focusing on greening port measures (Castellano et al., 2020; Hua et al., 2020; Munim et al., 2020; Sadek \& Elgohary, 2020). Following this stream, the idea of twinning digital and environmental activities has been elaborated by recent research outputs (Gerlitz \& Meyer, 2021; Zhou et al., 2021) with the overall objective to change the perspective on ports towards sustainable and smart development, utilising digital technology applications.

New initiatives such as the European Green Deal (EGD) or Sustainable and Smart Mobility Strategy of the European Commission are fostering and demanding a more sustainable development of ports, but also increase the pressure on seaports in terms of indicators to be achieved in 2035 and 2050. In addition, the United Nations 17 Sustainable Development Goals (SDGs) are producing additional challenges for seaports (Alamoush et al., 2021; Wang et al., 2020). To be more precise, the environmental target values are applicable for seaports as well, which requires mainly prototyping, piloting and capacity building according to the "Energy Technology Perspectives 2020" report published by the International European Agency. 
In this scene, small and medium-sized ports (SMSPs) notify additional barriers in their development, due to the fact that SMSPs suffer from lower trade volumes to bigger ports, but also face economic, geographic and environmental disadvantages ( $\mathrm{Lu}$ et al., 2018; Unctad, 2014). Furthermore, SMSPs have to deal with missing policy compliance (Puig et al., 2020) and disadvantages in fund allocation (Baltic Ports Organisation, 2021).

In the literature, there is no unified definition for aa SMSP (PAC2, 2014). The European Commission (EC) is defining ports' size according to their classification in the TEN-T network (EC, 2014). However, seaports' classification of small and medium-sized can also be implemented by their limited position in existing port clusters (Feng \& Notteboom, 2013) or regarding their lowermost positioning in port hierarchy in terms of costs and efficiency (Robinson, 1998). In addition, SMSPs can be defined by their main functionalities as enhancer for blue economy, actor in regionalisation processes and institution in multiport gateways (Notteboom, 2005, 2010; Feng \& Notteboom, 2013).

However, current literature identified missing tools on how SMSPs can be supported and strategically guided towards sustainable development (de Jong, 2020; Lawer et al., 2020; Mortensen et al., 2020). Especially when it comes to supportive measures for decision making in ports only little is known (Bjerkan \& Seter, 2019). This clearly narrows down the research gap. Hence, this paper aims to set up a benchmarking approach as a tool for improving strategic management in SMSPs that leads to cultural and institutional change (Clarke \& Manton, 1997; Prasnikar et al., 2005).

Attempts to set up a benchmarking on greening ports have been made in existing literature (Arof et al., 2021; Elzarka \& Elgazzar, 2014; Molavi et al., 2020a; Park et. al, 2019; Teerawattana \& Yang, 2019), but did not take into consideration SMSPs as specific research target group. In addition, the proposed approaches are concentrating on reduction of certain pollution values rather than strategic positioning of the ports for sustainable development. As this research attempts to add a new perspective on sustainable development by picking up the idea of twinning digital and environmental spheres, the benchmarking is based on the Digital Readiness Index for Ports (DRIP) (Philipp, 2020). The index was used in Connect2SmallPorts project, part-financed by Interreg South Baltic Programme 2014-2020 for data collection via audits in Baltic Sea ports. The overall aim of the index is to elaborate ports' readiness regarding their development towards a Smart Port. The idea of Smart Ports is on debate in research (Karas, 2020; Molavi et al., 2020b; Yang et al., 2020; Yau et al., 2020), leading to two main concepts of the Smart Port paradigm. On the one hand, Smart Ports are defined as fully automated and digitally connected ports (Yang et al., 2018). On the other hand, Smart Ports can be understood as a mindset of the port ecosystem towards a more holistic perspective putting smart use of resources with regard to environmental and energy impact into focus rather than the (digital) technologies itself (Molavi et al., 2020a; Port Technology, 2016). As the index follows a technology-driven approach to measure SMSPs' digital readiness and bearing in mind previous argumentation, applying a new perspective on the data can lead to new insights and findings regarding ports' potential for sustainable development. Hence, this research raises the following research question:

How does a digital and environmental twinning perspective affect SMSPs readiness for sustainable development?

To answer this research question, the DRIP methodology will be adjusted according to new insights, putting port management (Lam \& Notteboom, 2014; Notteboom et al., 2020; Peris-Mora, 2005) and human capital (Baranova \& Sorokin, 2017; Chen et al., 2017; Meletiou, 2006; Meyer et al., 2021) into more focus rather than technological dimension for sustainable development.

The research paper is organised as follows: after the introductory part, significant and used theoretical concepts will be illustrated. Afterwards, the used data and research methodology is presented. Followed by result presentation, the gained insights will be discussed and compared to other research findings in the particular field as well as concluding remarks emphasised.

\section{Theoretical Background}

The overview of existing topical literature confirms an emerging bulk of empirical and theoretical foundations pertaining to digital and environmental port transition. The research avenues on environmental sustainability in ports has not been widely studied to date (Asgari et al., 2015). The screened literature so far confirms growing needs to examine sustainability in ports. Yet, the majority of the research outputs concentrate around environmental aspects of sustainability (Kong \& Liu, 2021; Lalla-Ruiz et al., 2019; Puig et al., 2020; Rodrrigues et al., 2020) or corporate / social sustainability (Ashrafi et al., 2020; Denktas-Sakar \& Karatas-Cetin, 2012; Stein \& Acciaro, 2020), in particularly now in the face of the European need to enable environmental transition of European industry and economy, as 
encapsulated within the EGD Strategy. Research endeavours on holistic sustainability application in the context of ports are still mushrooming (Bjerkan \& Ryghaug, 2021; Damman \& Steen, 2021; Geerts et al., 2021; Kutznetsov et al., 2015; Lim et al., 2019; Vejvar et al., 2018). This is a paradox, since sustainability is referred to as key factor improving competitiveness and minimising risks (Parola et al., 2017). In this light, the authors call for a holistic perspective of digital and environmental transition in SMSPs by revitalising sustainability theory and transforming SMSPs into sustainable ones. There is no need to continue then the two-pronged approach on digital or environmental sustainability, resulting in myriads of concepts and trademarks, such as "green port", "eco-port", "smart port". A holistic perception of ports as sustainable ones entails all characteristics that can be ascribed either to one or another port category, namely, environmental responsibility, economic feasibility and social equity. Therefore, the present research strongly reconnects with and builds upon sustainability theory.

Sustainability is parsed as a holistic concept comprising domains of environmental, economic and social sustainability that need to be leveraged in terms of economic prosperity, environmental responsibility and social justice (Elkington, 1994), the so-called triple bottom line (TBL). In this, from economic perspective, cost minimisation, resource and operational efficiency are at the epicentre, while simultaneously reducing negative impacts from activities on the environment (Asgari et al. 2015; Di Vaio et al., 2015; Hossain et al., 2021; Sislian et al., 2016). When it comes to quantitative investigation of port sustainability performance, quantitative approach is dominating in the research. Yet, it is difficult to measure performance of port sustainability, since individual nature of each port, considering resources, operating environment, etc., resulted in rather limited possibilities to assess port sustainability (Lim et al., 2019). In the present research context focusing on SMSPS and similarities of these ports in terms of social and cognitive proximity as well as geographical proximity (Baltic Sea Region), quantitative performance investigation of port sustainability becomes feasible.

Bearing this in mind, sustainability is a multi-faceted phenomenon. There is no uniform theory of sustainability (Seuring \& Müller, 2008). Yet, in the context of ports, sustainability is built upon three key building blocks or pillars around economy, environment and society (Cheon, 2017; Cheon et al., 2017; Laxe et al., 2017). When it comes to port sustainability measures, the implementation thereof is affected by different factors, for instance international regulations, such as UN Convention on the Law of the Sea (UNCLOS), IMO Conventions for the Safety of Like at Sea (SOLAS), the International Convention for the Prevention of Pollution from Ships (MARPOL), Convention for Trade Facilitation (FAL) and Maritime Labour Convention (MLC). A series of EU directives and regulations on EU and national levels support sustainable performance of ports (Alamoush et al., 2021).

In 2016 the European Commission launched the "Port of the Future" initiative to encourage innovation in ports and strengthen the links with port cities. All approved projects aim at reinforcing port ecosystems and delivering synergies concerning environment, society, and economy benefits incl. technological interoperability, thus making ports and their interactions within own and city / hinterland ecosystems greener. Making greener means making more sustainable. In this light, modern sustainable management approaches, such as Corporate Social Responsibility (CSR) become crucial drivers for addressing and integrating sustainability aspects and practices into SMSPs activities (Acciaro, 2015; Lopez-Morales et al., 2020; Lu et al., 2016; Stein \& Acciaro, 2020). Indeed, CSR strategies are connected to a variety of advantages for ports, e.g. environmental efforts of ports generate positive images within port-city-hinterland interactions and among local community actors, thus building and strengthening trust (Puig et al., 2015). In addition, competitive strength of CSR for ports is associated with differentiation of services by e.g. operations in environmentally sensitive areas, better recognition among employees, reduction of information costs through transparency increase and easier access to investments, attracting more customers (Drobetz et al., 2014) as well as ability to innovate and accomplish various sustainable development objectives (Cheon et al., 2017).

However, despite positive potentials associated with the CSR in ports, its implementation is rather hard to track. On the one hand, it is because ports are keen in the first move to achieve economic feasibility in a short-run. Only then environmental and social responsibility actions are crucial for the. On the other hand, ports are exposed to harsh external pressure, e.g. where customers are not willing to pay, for instance, higher environmental taxes. One potential source of change is associated with institutional change, i.e. alignment of sustainability strategies with internal goals, support of policy makers and new incentives, accompanied by training and education needs, in particular in SMSPs that face scarcity of skilled personnel in rural areas ((Vejvar et al., 2018). Another source of improvement pinpoints cultural change from all private and public actors that build up the port network and ecopsystem, including new public policies and strategies (Duran et al., 2021).

In being or becoming sustainable, ports as ecosystems become crucial drivers of sustainable development, as noted by the WCED (1987), namely sustainability and sustainable development stand for 
meeting "needs of the present without compromising the ability of future generations to meet their own needs" (p. 43). Sustainable development brings in society social equity, in business - economic efficiency, in environment - environmental responsibility. As a result, the intertwining links of sustainable aspects and port interactions also considers the $17 \mathrm{UN}$ SDGs and thus contributes to sustainable development (Koberg \& Langoni, 2019; Stoddart et al., 2011). In this sense, it is essential to strengthen SMSPs performance in all sustainability domains.

\section{Methodology and Data}

As introduced, the conducted research is based on implemented audits in small and medium-sized ports of the Baltic Sea Region. In total, 38 ports have participated in the audits, which have been implemented as structured interviews or via an online questionnaire using the DRIP score benchmarking model (Philipp, 2020). Data collection as well as research activities have been supported by the Connect2SmallPorts project, part-financed by Interreg South Baltic Programme 2014-2020.

One key element of the used DRIP methodology is the alignment of all 44 indictors into five dimensions (including their weights): Management (20\%), Human Capital (20\%), Functionality (25\%), Technology (30\%) and Information (5\%). The weighting follows gained insights of the project implementation (Philipp et al., 2020). Hence, as stated in the introduction, recent research stream is moving towards a more sustainable perspective of port development. Therefore, this conducted research is re-elaborating the weighting of each dimension with focus on conclusions for SMSPs' readiness towards sustainable development. Hence, this research is using a "sustainable Balanced Scorecard for Ports" (sBSP) as adaptation of the original DRIP score, which will have a higher focus on the dimensions of Management (Munim et al., 2020; Nitsenko et al., 2017; Notteboom et al., 2020) and Human Capital (Baranova \& Sorokin, 2017; Meletiou, 2006; Meyer et al., 2021; Zhu et al., 2018) rather than the technical dimensions. Thus, the following adaptation has been elaborated in the conducted research:

Table 1. Dimension comparison of sBSP and DRIP scores

\begin{tabular}{|l|l|l|}
\hline Dimension & DRIP & sBSP \\
\hline Management & $20 \%$ & $30 \%$ \\
\hline Human Capital & $20 \%$ & $30 \%$ \\
\hline Functionality & $25 \%$ & $20 \%$ \\
\hline Technology & $30 \%$ & $20 \%$ \\
\hline Information & $5 \%$ & Indicators re-aligned \\
\hline
\end{tabular}

Source: Compiled by authors (ref. Philipp, 2020)

As illustrated in Table 1, the sBSP is not only changing the weights, but also excluding the dimension of Information by re-aligning the indicators to other dimensions or deleting them completely. Table 2 provides an overview of the new allocation for each indicator listed in the Information dimension including the theoretical rationale behind based on research records.

Table 2. Reallocation of Information indicators in sBSP

\begin{tabular}{|l|l|l|}
\hline $\begin{array}{l}\text { Information indicator according to the DRIP } \\
\text { methodology }\end{array}$ & Dimension in sBSP & Research record \\
\hline Personal Network & Management & $\begin{array}{l}\text { Chatti, 2012 } \\
\text { Horlings \& Padt, 2013 }\end{array}$ \\
\hline Printed Media & deleted & De Azevedo et al., 2018 \\
\hline Internet & Functionality & Zelenika \& Pearce, 2013 \\
\hline Social Media Resources & Management & Lee, 2017 \\
\hline Fairs & Management & $\begin{array}{l}\text { Geigenmüller, 2010 } \\
\text { Siemieniako \& Gebarowski, 2017 }\end{array}$ \\
\hline Conferences & Human Capacity & Farazmand, 2004 \\
\hline Associations & Management & Jepson Jr, 2001 \\
\hline Scientific Institutions & Management & $\begin{array}{l}\text { Ashrafi } \text { et al., 2020 } \\
\text { Hossain } \text { et al., 2021 }\end{array}$ \\
\hline Source Compiled by authors &
\end{tabular}

For each of the 43 used indicators - as Printed Media is deleted in the used database - an answer scale from 1 to 6 was used, whereas 6 is the highest score towards a smart port (Philipp, 2020). Within the mentioned dimensions, the average score of all listed indicators is used. Based on that and acknowledging the weightings of each dimension, the final score is calculated for each port, allowing a classification depending on the individual score. Table No. 3 illustrates the introduced port classifications of the DRIP score, which have been re-used for the conducted research and sBSP calculation as well. 
Table 3. Port Classification according to DRIP / sBSP

\begin{tabular}{|l|l|l|}
\hline Port Classification & Characteristics & DRIP / sBSP score (x) \\
\hline Smart Port & $\begin{array}{l}\text { The port is completely connected via a communications network and } \\
\text { fully integrated with its environment (i.e. all stakeholders of the } \\
\text { industry) as well as other ports and logistics actors around the globe. }\end{array}$ & $5.5 \leq \mathrm{x} \leq 6.0$ \\
\hline Developer Port & $\begin{array}{l}\text { The port and the hinterland players are connected through one single } \\
\text { digital environment, the advantages of the previous stages are } \\
\text { extended to even more stakeholders. }\end{array}$ & $4.5 \leq \mathrm{x}<5.5$ \\
\hline \multirow{5}{*}{ Adopter Port } & $\begin{array}{l}\text { The port and immediately involved organisations (regularly: } \\
\text { authority, operator, customs, etc.) started to integrate } \\
\text { their (information) systems in order to achieve better } \\
\text { communication. }\end{array}$ & $3.5 \leq \mathrm{x}<4.5$ \\
\hline Monitor Port & $\begin{array}{l}\text { Individual automations in the port might emerge. Port authority, } \\
\text { operator and related organisations in the near proximity of the port } \\
\text { maintain their own processes and databases as well as started to } \\
\text { digitalise them individually. }\end{array}$ & $2.5 \leq \mathrm{x}<3.5$ \\
\hline \multirow{3}{*}{ Analog Port } & $\begin{array}{l}\text { Automation do not exist. The port has no or less knowledge about } \\
\text { digitalisation and thus, do not know how to change or is not willing. } \\
\text { Furthermore, the port performs usually the landlord functions. }\end{array}$ & $1.0 \leq \mathrm{x}<2.5$ \\
\hline
\end{tabular}

Source: Compiled by authors (ref. Philipp, 2020, p.56).

As the research path is based on the previous developed DRIP score, the implemented research methods are identical to the previous research (ref. to Philipp, 2020). Hence, this research is based on a qualitative approach with an inductive perspective (Thomas, 2003, 2006) where the participating ports are seen as case studies. In addition, the research claims to have a deductive perspective as well by scrutinising port performance benchmarking and greening ports concepts of topical literature. Thus, the research study applies a hybrid research approach (Fereday \& Muir-Cochrane, 2006), which combines inductive and deductive approaches.

Furthermore, the participating SMSPs are considered as case studies, using a "how" questions as basic research question and following Yen's definition of cases being phenomena in real life context with unknown connections and little or no control by the researchers (Yanzan, 2015; Yin, 2018). Furthermore, the research followed an exploratory path for undiscovered insights and knowledge in the particular research field of SMSPs benchmarking towards sustainable development (Pantano \& Vannucci, 2019; Shields \& Rangarajan, 2013).

The conducted research can be summarised as follows:

- Research approach: qualitative methods

- Research tool: DRIP score and audits of 38 Baltic SMSPs

- Research scope: 01/2020 - 03/2021

- Research types: analytical, exploratory

- Research methods: qualitative - case studies, desk research

Furthermore, the research is based on positivism and interpretivism of the researchers (ref. to Mertens, 2010; Creswell, 2013). The research was undertaken to the best of researcher's knowledge with attention to research ethics and habits. The gathered data is the property of the Connect2SmallPorts project.

In sum, the implemented research followed a comprehensive journey, by addressing different aspects and combining two European growth policies with focus on potential key actors - small and medium-sized ports.

\section{Results}

In the following chapter, the results gathered from the complied data are presented. First, the DRIP score values will be compared to the sBSP classifying the participating port according to TEN-T network (European Commission, 2014). Afterwards, the analysis scope changes to the port classification as presented in Table 3 highlighting the differences for ports when moving to a more sustainable perspective used in the sBSP.

As the TEN-T classification is one of the common tools applicable to define ports as introduced earlier, it is used to produce conclusions of the results for SMSPs in terms of their potential for sustainable development. Hence, the results from the sBSP are compared to the original DRIP score values for Core, Comprehensive and non-TEN-T ports which participated in the audits as averages of all ports. Table 4 shows the results as averages of all ports in the respective class. 
Table 4. Comparison of DRIP and sBSP results

\begin{tabular}{|l|l|l|}
\hline Classification acc. to TEN-T & DRIP & sBSP \\
\hline non-TEN-T & 3.267 & 3.316 \\
\hline Comprehensive & 3.871 & 3.478 \\
\hline Core & 4.358 & 4.290 \\
\hline \multicolumn{2}{|l|}{} \\
\begin{tabular}{|l|l|l|}
\hline Port Classification & DRIP & sBSP \\
\hline Analog Port & 1.827 & 2.098 \\
\hline Monitor Port & 3.073 & 3.174 \\
\hline Adopter Port & 3.872 & 3.679 \\
\hline Developer Port & 4.847 & 4.844 \\
\hline Smart Port & not identified & not identified \\
\hline
\end{tabular}
\end{tabular}

Source: Compiled by authors

Starting with the TEN-T classification, on the one hand side the average value for Core and Comprehensive ports is decreasing from 3.871 to 3.478 and 4.358 to 4.290 . On the other hand, the value of sBSP for non-TEN-T listed ports is higher than in the original DRIP - from 3.267 to 3.316. SMSPs as research target are mainly represented in this group, showing increasing values when changing the perspective towards a more sustainable understanding of a Smart Port rather than a high technical view, while Comprehensive and Core Port offer a decrease.

The second part of Table 4 supports these results, as the majority of SMSPs have been identified in the classes of Analog, Monitor and Adopter Port. Especially those ports that have been elaborated with rather low scores in the original DRIP (Analog and Monitor Port) emphasise an increase in their score within the adaptation of sBSP - from 1.827 to 2.098 and 3.073 to 3.174. However, the group of Analog and Developer Ports offer slightly decreased values -3.872 to 3.679 and 4.847 to 4.844 . Additionally, in both cases no Smart Port was identified following this research methodology.

Drawing back to the research question, the first classification is preferred when developing conclusions and theorems out of the yielded results. In this case, audited ports are situated in the same class in both approaches DRIP and sBSP. Due to the idea of the port classifications in the second approach, few ports have changed their class as their final scores have been recalculated with the new weighting. This, for example, explains the higher value for Analog Port class, as one port was aligned to this class as the new score decreased barely beyond the value limit of 2.5 (see Table 3).

\section{Discussion}

As the yielded results indicate, modifying the benchmarking from highly technical to a more sustainable perspective on the pathway to the Smart Port paradigm puts SMSPs into a better position for future development. Table No. 4 has shown that non-TEN-T ports which are per definition smaller ports (EC, 2013) benefitted from the adaptation made in the sBSP. This of course results also from the lower weighting of digital infrastructure, which is mainly missing in smaller ports (Feng \& Notteboom, 2013; Gerlitz \& Meyer, 2021).

As the research has paid more attention to the Management and Human Capital dimension for port development, it is in line with existing literature emphasising their great value in port development (Notteboom et al., 2020; Saadat \& Saadat, 2016; Zhu et al., 2018) and especially in terms of innovation for smaller ports (Meletiou, 2006; Meyer et al., 2021) as they play a key role in sustainable development (Damman \& Steen, 2021).

Additionally, the research contributes to current literature scope as digital and environmental twinning has been put into the centre of the research design. Though, benchmarking attempts of sustainable port development are lacking on a holistically view of affected perspectives (Asgari et al., 2015). Thus, this research contributes to the current literature with a novel approach by adapting a digital benchmarking towards a sustainable benchmarking.

Nevertheless, benchmarking analysis is providing a status rather than a progress, but serves as decision making toll for ports (Ansorena, 2021) which is highly required in port management (Bjerkan \& Seter, 2019). Hence, this research theoretically contributes to this identified research gap.

Despite the research methodology was designed to the best of knowledge of the authors, some limitations need to be discussed. As the auditing was implemented with one representative of each participating Baltic seaport, the yielded values might be biased. Even though, the researcher approached representatives on management level, the critic of subjective inputs holds (Hill et al., 1996).

Additionally, the conducted research is contributing to the on-going discussion on how to understand a Smart Port. Two mainstreams are existing in current literature, emphasising a technical 
perspective by defining a Smart Port as fully automated with digital connection of all devices (Yang et al., 2018), on the one hand side and a Smart Port perspective based on resource efficiency with respect to the environmental and sustainable development on the other hand (Molavi et al., 2020; Port Technology, 2016). Since this research has focused on SMSPs, it adds this specific group to the overall research discussion. Based on the literature and research results, the Smart Port definition for SMSPs needs to be discussed in a sustainable view rather than technical or digital. Thus, for SMSPs the second illustrated Smart Port idea is more appropriate, due to their nature of being regional actors in an ecosystem rather than a single entity (Gerlitz \& Meyer, 2021).

\section{Conclusions}

The purpose of this research paper was to examine the digital and environmental twinning perspective's impact on measuring SMSPs readiness for sustainable development. As the results have shown, changing the position from a digital to a more sustainable benchmarking indicates a positive impact on SMSPs readiness for future development. For the benchmarking, the already existing and applied DRIP score was used. Due to recent literature finding and streams on Sustainable and Smart Ports, an adaptation of the original index was introduced - the sBSP score with new weightings on key dimensions for sustainable port development.

The adaptation clearly referred to the importance of Management and Human Capital dimension in a port ecosystem when it comes to sustainable development. Thus, their weights have been increased compared to the other dimensions of Technology and Functionality. In addition, the indicators previous listed in Information dimension have been reallocated to one of the other four dimensions based on literature records. Hence, the new calculation allowed a comparison using the same dataset of the DRIP and sBSP score.

As results have shown, SMSPs benefitted from this change of mindset, putting resource efficiency and sustainable development into the centre of the Smart Port idea. In this vein, the management and human capital in a port ecosystem have been seen as main drivers for port ecosystem development rather than digital technologies. However, based on the designed research and implemented benchmarking, future research has to consider a more tailor-made benchmarking methodology when elaborating SMSPs in terms of digitalisation, environment, energy efficiency and / or smartness. Especially when it comes to Key Enabling Technologies, a non-existence of any system in the port ecosystem is valued negatively. Instead, in a previous step the SMSPs' individual demand for a certain technology should be assessed, since, for example, digital technologies are not needed or applicable in a smaller port and should not be considered when analysing the sustainable development of a SMSP. Hence, port performance indices used in SMSPs tend to result in too negative scores for the ports. Thus, future research needs to analyse on how to consider the individual characteristics of SMSPs in benchmarking approaches too.

\section{References}

1. Acciaro, M. (2015) Corporate responsibility and value creation in the port sector. International Journal of Logistics Research and Applications, 18(3), 291-311.

2. Alamoush, A. S., Ballini, F., \& Dalaklis, D. (2021) Port sustainable supply chain management framework: Contributing to the United Nations' sustainable development goals. Maritime Technology and Research, 3(2), 137-161.

3. Ansorena, I. L. (2021) On the benchmarking of port performance. A cosine similarity approach. International Journal of Process Management and Benchmarking, 11(1), 101-114.

4. Arof, A. M., Zakaria, A., \& Rahman, N. S. F. A. (2021) Green Port Indicators: A Review. Advanced Engineering for Processes and Technologies II, 237-256.

5. Asgari, N., Hassani, A., Jones, D., \& Nguye, H. H. (2015) Sustainability ranking of the UK major ports: Methodology and case study. Transportation Research Part E: Logistics and Transportation Review, 78, 19-39.

6. Ashrafi, M., Walker, T. R., Magnan, G. M., Adams, M., \& Acciaro, M. (2020) A review of corporate sustainability drivers in maritime ports: a multi-stakeholder perspective. Maritime Policy \& Management, 47(8), 1027-1044.

7. Baltic Ports Organisation (2021) Comprehensive ports in the Baltic Sea - an important role for Short Sea Shipping, people mobility, industries and blue economy.

8. Baranova, N. M., \& Sorokin, L. V. (2017) An impact of human capital on the sustainable economic development. Economic Analysis: Theory and Practice, 16(12), 2224-2237. 
9. Bjerkan, K. Y., \& Ryghaug, M. (2021) Diverging pathways to port sustainability: How social processes shape and direct transition work. Technological Forecasting and Social Change, 166, 120595.

10. Bjerkan, K. Y., \& Seter, H. (2019) Reviewing tools and technologies for sustainable ports: Does research enable decision making in ports? Transportation Research Part D: Transport and Environment, 72, 243-260.

11. Castellano, R., Ferretti, M., Musella, G., \& Risitano, M. (2020) Evaluating the economic and environmental efficiency of ports: Evidence from Italy. Journal of Cleaner Production, 271, 122560.

12. Chatti, M. A. (2012) Knowledge management: a personal knowledge network perspective. Journal of knowledge management.

13. Chen, Y. Z., Zhou, L. C., Zhou, Y. X., Shen, R. C., Wenzhou, E. E. I., \& Quarantine, B. (2017) Analysis on the core capacity building of different kinds of ports. Chinese Journal of Frontier Health and Quarantine, 02.

14. Cheon, S. (2017) The economic-social performance relationships of ports: Roles of stakeholders and organizational tension. Sustainable Development, 25(1), 50-62. doi:10.1002/sd.1641

15. Cheon, S., Maltz, A., \& Dooley, K. (2017) The link between economic and environmental performance of the top 10 US ports. Maritime Policy \& Management, 44(2), 227-247.

16. Clarke, A., \& Manton, S. (1997) A benchmarking tool for change management. Business Process Management Journal.

17. Damman, S., \& Steen, M. (2021) A socio-technical perspective on the scope for ports to enable energy transition. Transportation Research Part D: Transport and Environment, 91, 102691.

18. De Azevedo, A. R., Alexandre, J., Xavier, G. D. C., \& Pedroti, L. G. (2018) Recycling paper industry effluent sludge for use in mortars: a sustainability perspective. Journal of Cleaner Production, 192, 335-346.

19. De Jong, J. (2020) Servitization in the Shipbuilding Industry: A research into the relation of user profiles and service contracts of high-speed transport vessels.

20. Denktas-Sakar, G., \& Karatas-Cetin, C. (2012) Port sustainability and stakeholder management in supply chains: A framework on resource dependence theory. The Asian Journal of Shipping and Logistics, 28(3), 301-319.

21. Di Vaio, A., Varriale, L., \& Alvino, F., (2018) Key performance indicators for developing environmentally sustainable and energy efficient ports: Evidence from Italy. Energy Policy, 122, 229-240.

22. Drobetz, W., Merikas, A., Merika, A., \& Tsionas, M. G. (2014) Corporate social responsibility disclosure: The case of international shipping. Transportation Research Part E: Logistics and Transportation Review, 71, 18-44.

23. Durán, C., Palominos, F., Carrasco, R., \& Carrillo, E. (2021) Influence of Strategic Interrelationships and Decision-Making in Chilean Port Networks on Their Degree of Sustainability. Sustainability, 13(7), 3959.

24. Elkington, J. (1994) Towards the sustainable corporation: Win-win-win business strategies for sustainable development. California Management Review, 36(2), 90-100.

25. Elzarka, S., \& Elgazzar, S. (2014) Green port performance index for sustainable ports in Egypt: a fuzzy AHP approach. In: International Forum on Shipping, Ports and Airports (IFSPA) 2014: Sustainable Development in Shipping and Transport Logistics.

26. European Commission (2013) Regulation (EU) No 1315/2013 of the European Parliament and of the Council of 11 December 2013 on Union guidelines for the development of the trans-European transport network and repealing Decision No 661/2010/EU. Official Journal of the European Union, $1-128$.

27. European Commission (2014) List of Seaports in the Core and Comprehensive Network.

28. Farazmand, A. (2004) Innovation in Strategic Human Resource Management: Building Capacity in the Age of Globalization. Public Organization Review, 4, 3-24. https://doi.org/10.1023/B:PORJ.0000015649.54219.b7

29. Feng, L., \& Notteboom, T. (2013) Peripheral challenge by small and medium sized ports (SMSPs) in multi-port gateway regions: the case study of northeast of China. Polish Maritime Research, 20(Special-Issue), 55-66.

30. Fereday, J., \& Muir-Cochrane, E. (2006) Demonstrating rigor using thematic analysis: A hybrid approach of inductive and deductive coding and theme development. International journal of qualitative methods, 5(1), 80-92.

31. Geerts, M., Dooms, M., \& Stas, L. (2021) Determinants of Sustainability Reporting in the Present Institutional Context: The Case of Port Managing Bodies. Sustainability, 13(6), 3148. 
32. Geigenmüller, A. (2010) The role of virtual trade fairs in relationship value creation. Journal of Business \& Industrial Marketing.

33. Gerlitz, L., \& Meyer, C. (2021) Small and Medium-Sized Ports in the TEN-T Network and Nexus of Europe's Twin Transition: The Way towards Sustainable and Digital Port Service Ecosystems. Sustainability, 13(8), 4386.

34. Hill, M., Mann, L., \& Wearing, A. J. (1996) The effects of attitude, subjective norm and self-efficacy on intention to benchmark: a comparison between managers with experience and no experience in benchmarking. Journal of Organizational Behavior, 17(4), 313-327.

35. Horlings, I., \& Padt, F. (2013) Leadership for sustainable regional development in rural areas: Bridging personal and institutional aspects. Sustainable Development, 21(6), 413-424.

36. Hossain, T., Adams, M., \& Walker, T. R. (2021) Role of sustainability in global seaports. Ocean \& Coastal Management, 202, 105435.

37. Hua, C., Chen, J., Wan, Z., Xu, L., Bai, Y., Zheng, T., \& Fei, Y. (2020) Evaluation and governance of green development practice of port: A sea port case of China. Journal of Cleaner Production, 249, 119434.

38. Jepson Jr, E. J. (2001) Sustainability and planning: Diverse concepts and close associations. Journal of planning literature, 15(4), 499-510.

39. Karaś, A. (2020) Smart port as a key to the future development of modern ports. TransNav: International Journal on Marine Navigation and Safety of Sea Transportation, 14(1).

40. Koberg, E., \& Longoni, A. (2019) A systematic review of sustainable supply chain management in global supply chains. Journal of Cleaner Production, 207, 1084-1098. doi:10.1016/j.jclepro.2018.10.033

41. Kong, Y., \& Liu, J. (2021) Sustainable port cities with coupling coordination and environmental efficiency. Ocean \& Coastal Management, 205, 105534.

42. Kuznetsov, A., Dinwoodie, J., Gibbs, D., Sansom, M., \& Knowles, H. (2015) Towards a sustainability management system for smaller ports. Marine Policy, 54, 59-68.

43. Lalla-Ruiz, E., Heilig, L., \& Voß, S. (2019) Environmental sustainability in ports. In: Sustainable transportation and smart logistics, 65-89. Elsevier.

44. Lawer, E. T., Herbeck, J., \& Flitner, M. (2019) Selective adoption: How port authorities in Europe and West Africa Engage with the globalizing 'Green Port'idea. Sustainability, 11(18), 5119.

45. Laxe, F. G., Bermúdez, F. M., Palmero, F. M., \& Novo-Corti, I. (2017) Assessment of port sustainability through synthetic indexes: Application to the Spanish case. Marine Pollution Bulletin, $119(1), 220-225$

46. Lee, Y. C. (2017) Corporate sustainable development and marketing communications on social media: Fortune 500 enterprises. Business Strategy and the Environment, 26(5), 569-583.

47. Lim, S., Pettit, S., Abouarghoub, W., \& Beresford, A. (2019) Port sustainability and performance: A systematic literature review. Transportation Research Part D: Transport and Environment, 72, 47-64.

48. Lirn, T. C., Wu, Y. C. J., \& Chen, Y. J. (2013) Green performance criteria for sustainable ports in Asia. International Journal of Physical Distribution \& Logistics Management.

49. López-Morales, J. S., Huerta-Estévez, A., Andrade-Estrada, M. G., \& Zarrabal-Gutiérrez, C. G. (2020) Corporate social responsibility in ports of Latin America. Marine Economics and Management.

50. Lu, C. S., Lai, P. L., \& Chiang, Y. P. (2016) Container terminal employees' perceptions of the effects of sustainable supply chain management on sustainability performance. Maritime Policy \& Management, 43(5), 597-613.

51. Lu, W., Park, S. H., Oh, J. G., \& Yeo, G. T. (2018) Network connection strategy for Small and Medium-sized Ports (SMSPs). The Asian Journal of Shipping and Logistics, 34(1), 19-26.

52. Meletiou, M., \& Law, L. (2006) Improved port performance through training: The contribution of the International Labour Organization. In: 22nd International Port Conference. Human Resources and Sea Ports Performance, 12-14.

53. Meyer, C., Gerlitz, L., \& Henesey, L. (2021) Cross-Border Capacity Building for Port Ecosystems in Small and Medium-Sized Ports. Journal of European Studies, 11 (1), 33.

54. Molavi, A., Lim, G. J., \& Race, B. (2020a) A framework for building a smart port and smart port index. International journal of sustainable transportation, 14(9), 686-700.

55. Molavi, A., Shi, J., Wu, Y., \& Lim, G. J. (2020b) Enabling smart ports through the integration of microgrids: A two-stage stochastic programming approach. Applied Energy, 258, 114022.

56. Mortensen, L., Kørnøv, L., Lyhne, I., \& Raakjær, J. (2020) Smaller ports' evolution towards catalysing sustainable hinterland development. Maritime Policy \& Management, 47(3), 402-418. 
57. Munim, Z. H., Sornn-Friese, H., \& Dushenko, M. (2020) Identifying the appropriate governance model for green port management: Applying Analytic Network Process and Best-Worst methods to ports in the Indian Ocean Rim. Journal of Cleaner Production, 268, 122156.

58. Nitsenko, V. S., Nyenno, I. M., Kryukova, I., Kalyna, T., \& Plotnikova, M. (2017) Business model for a sea commercial port as a way to reach sustainable development goals.

59. Notteboom, T. E. (2005) The peripheral port challenge in container port systems. International maritime transport: perspectives, 173-188.

60. Notteboom, T. E. (2010) Concentration and the formation of multi-port gateway regions in the European container port system: an update. Journal of transport geography, 18(4), 567-583.

61. Notteboom, T., Lugt, L. V. D., Saase, N. V., Sel, S., \& Neyens, K. (2020) The role of seaports in green supply chain management: Initiatives, attitudes, and perspectives in Rotterdam, Antwerp, North Sea Port, and Zeebrugge. Sustainability, 12(4), 1688.

62. Pantano, E., \& Vannucci, V. (2019) Who is innovating? An exploratory research of digital technologies diffusion in retail industry. Journal of Retailing and Consumer Services, 49, 297-304.

63. Park, Y. S., Mohamed Abdul Ghani, N. M. A., Gebremikael, F., \& Egilmez, G. (2019) Benchmarking environmental efficiency of ports using data mining and RDEA: the case of a US container ports. International Journal of Logistics Research and Applications, 22(2), 172-187.

64. Parola, F., Risitano, M., Ferretti, M., \& Panetti, E. (2017) The drivers of port competitiveness: a critical review. Transport Reviews, 37(1), 116-138.

65. Philipp, R. (2020) Digital readiness index assessment towards smart port development. In: Sustainability Management Forum, Nachhaltigkeits Management Forum, 28, 49-60. Springer Berlin Heidelberg.

66. Philipp, R., Gerlitz, L., Moldabekova, A. (2020) Small and medium-sized seaports on the digital track: tracing digitalization across the south Baltic region by innovative auditing procedures. In: Kabashkin, I., Yatskiv, I., Prentkovskis, O. (eds) Relstat 2019. Lecture notes in network and systems, 117. Springer, Cham, pp. 351 - 362. https://doi.org/10.2478/rtuect-2019-0081

67. Port Technology. (2016) What is a Smart Port? Retrieved from https://www.porttechnology.org/news/what_is_a_smart_port/ (Accessed: 11.05.2021).

68. Prašnikar, J., Debeljak, Ž., \& Ahčan, A. (2005) Benchmarking as a tool of strategic management. Total Quality Management and Business Excellence, 16(2), 257-275.

69. Puig, M., Raptis, S., Wooldridge, C., \& Darbra, R. M. (2020) Performance trends of environmental management in European ports. Marine pollution bulletin, 160, 111686.

70. Puig, M., Wooldridge, C., Michail, A., \& Darbra, R. M. (2015) Current status and trends of the environmental performance in European ports. Environmental Science \& Policy, 48, 57-66.

71. Robinson, R. (1998) Asian hub/feeder nets: the dynamics of restructuring. Maritime Pol. Management, 25 (1), 21-40. 931

72. Saadat, V., \& Saadat, Z. (2016) Organizational learning as a key role of organizational success. Procedia-Social and Behavioral Sciences, 230, 219-225.

73. Sadek, I., \& Elgohary, M. (2020) Assessment of renewable energy supply for green ports with a case study. Environmental Science and Pollution Research, 27(5), 5547-5558.

74. Seuring, S., \& Müller, M. (2008) Core issues in sustainable supply chain management-a Delphi study. Business strategy and the environment, 17(8), 455-466.

75. Shields, P. M., \& Rangarajan, N. (2013) A playbook for research methods: Integrating conceptual frameworks and project management. New Forums Press.

76. Siemieniako, D., \& Gębarowski, M. (2017) B2B trade fairs and promise management as a relationship marketing concept. Journal of Customer Behaviour, 16(3), 237-261.

77. Sislian, L., Jaegler, A., \& Cariou, P. (2016) A literature review on port sustainability and ocean's carrier network problem. Research in Transportation Business \& Management, 19, 19-26.

78. Stein, M., \& Acciaro, M. (2020) Value Creation through Corporate Sustainability in the Port Sector: A Structured Literature Analysis. Sustainability, 12(14), 5504.

79. Stoddart, H., Schneeberger, K., Dodds, F., Shaw, A., Bottero, M., Cornforth, J., \& White, R. (2011) A pocket guide to sustainable development governance. Stakeholder Forum 2011.

80. Teerawattana, R., \& Yang, Y. C. (2019) Environmental performance indicators for green port policy evaluation: case study of Laem Chabang port. The Asian Journal of Shipping and Logistics, 35(1), 63-69.

81. Thomas, D. R. (2003) A general inductive approach for qualitative data analysis.

82. Thomas, D. R. (2006) A general inductive approach for analyzing qualitative evaluation data. American journal of evaluation, 27(2), 237-246. 
83. Unctad (2014) Review of Maritime Transport 2014.

84. Vejvar, M., Lai, K. H., Lo, C. K., \& Fürst, E. W. (2018) Strategic responses to institutional forces pressuring sustainability practice adoption: Case-based evidence from inland port operations. Transportation Research Part D: Transport and Environment, 61, 274-288.

85. Wakeman, R. (1996) What is a sustainable port? The relationship between ports and their regions. Journal of Urban Technology, 3(2), 65-79.

86. Wang, X., Yuen, K. F., Wong, Y. D., \& Li, K. X. (2020) How can the maritime industry meet Sustainable Development Goals? An analysis of sustainability reports from the social entrepreneurship perspective. Transportation Research Part D: Transport and Environment, 78, 102173.

87. WCED, S. W. S. (1987) World commission on environment and development. Our common future, 17(1), 1-91.

88. Yang, Y., Xue, X., Gao, Y., Zhang, H., \& Du, X. (2020) Constructing Sustainable Coastal Ecological Environment: A Hierarchical Structure for Sustainable Smart Ports. Journal of Coastal Research, 99(SI), 358-363.

89. Yang, Y., Zhong, M., Yao, H., Yu, F., Fu, Y. \& Postolache, O. (2018) Internet of Things for small ports: Technologies and challenges. IEEE Instrumentatino \& measurement Magazine, 21(1), 34-43. https://doi.org/10.1109/MIM.2018.8278808

90. Yazan, B. (2015) Three approaches to case study methods in education: Yin, Merriam, and Stake. Qual. Rep., 20, 134-152.

91. Yau, K. L. A., Peng, S., Qadir, J., Low, Y. C., \& Ling, M. H. (2020) Towards Smart Port Infrastructures: Enhancing Port Activities Using Information and Communications Technology. IEEE Access, 8, 83387-83404.

92. Yin, R.K. (2018) Case Study Research and Applications; Sage: Thousand Oaks, CA, USA.

93. Zelenika, I., \& Pearce, J. M. (2013) The Internet and other ICTs as tools and catalysts for sustainable development: innovation for 21st century. Information Development, 29(3), 217-232.

94. Zhou, C., Xu, J., Miller-Hooks, E., Zhou, W., Chen, C. H., Lee, L. H., ... \& Li, H. (2021) Analytics with digital-twinning: A decision support system for maintaining a resilient port. Decision Support Systems, 143, 113496.

95. Zhu, Q., Krikke, H., \& Caniels, M. C. (2018) Supply chain integration: value creation through managing inter-organizational learning. International Journal of Operations \& Production Management. 